\title{
Dynamic modelling of Alkaline self-pressurized electrolyzers: a phenomenological-based semiphysical approach
}

\author{
Martín David ${ }^{\mathrm{a}, \mathrm{b}, *}$, Hernán Alvarez ${ }^{\mathrm{c}}$, Carlos Ocampo-Martinez ${ }^{\mathrm{b}}$, Ricardo \\ Sánchez-Peña ${ }^{\mathrm{a}}$ \\ ${ }^{a}$ Instituto Tecnológico Buenos Aires (ITBA) and Consejo Nacional de Investigaciones Científicas \\ y Técnicas (CONICET), Ciudad Autónoma de Buenos Aires, Argentina \\ ${ }^{b}$ Automatic Control Department, Universitat Politècnica de Catalunya, Institut de Robòtica $i$ \\ Informàtica Industrial (CSIC-UPC), Barcelona, España \\ ${ }^{c}$ Processes and Energy Department, Universidad Nacional de Colombia, Kalman Research Group, \\ Medellín, Colombia
}

\begin{abstract}
This paper proposes a phenomenological based semiphysical model (PBSM) for a self-pressurized alkaline electrolyzer. The model, based on mass and energy balances, represents the dynamic behavior of hydrogen and oxygen production using electrolysis. The model allows to anticipate operational variables as dynamic responses in the concentrations of the electrolytic cell, and variations in both, level and pressure, at the gas separation chambers due to the change in electric current. The model parameters have been adjusted based on experimental measurements taken from an available prototype and through a suitable identification process. Simulation results replicate the current dynamic response of the experimental self-pressurized electrolyzer assembly. This model proves to be useful in the improvement of the control of gas production rate in this kind of assemblies, both as a validated simulation platform and as a source of reduced order models for model-based control design.
\end{abstract}

Keywords: Hydrogen, Alkaline electrolysis, Dynamic modelling, Phenomenological-based semiphysical modelling

\section{Introduction}

It is widely accepted that the current environmental situation is critical due to the growing generation of greenhouse gases (GHG) [1,2]. Consequently, research and protection policies are developed throughout the world to reduce GHG emissions. In that sense, the implementation of renewable energy depends on the possibility of storing the excess of energy for its use when there is a greater demand. Among the methods of energy storage, hydrogen production currently takes relevance due to its energy density, high capacity and portability [3, 4, 5].

\footnotetext{
*Corresponding author

Email address: mdavid@itba.edu.ar (Martín David)
} 
Among all the methods of hydrogen production, electrolysis holds a dominant position on the use of the fluctuating electricity from renewable energy, due to its ease of connection with these sources, production of high purity hydrogen and current infrastructure. While the electrolysis was the first commercial method for obtaining hydrogen [6], other cheaper methods are today used at industrial level. However, given the new interest in caring for the environment, electrolysis takes back relevance and further research is aimed at improving efficiency and reducing costs. Ogawa et al [7] analyse the citations made in recent years on electrolysis concluding that the area of catalysts in alkaline electrolyzers is attracting greater interest, which can be seen in $[8,9]$.

Regarding the authors' contribution to the development of alkaline electrolysis, so far four alkaline self-pressurized electrolysis prototypes have been developed at the Instituto Tecnológico de Buenos Aires (ITBA), following now by the modelling and control design to optimize their production capacity.

Several authors have been described the operation principle of alkaline cells. Most of those works are focused on stationary regime and based in empirical analysis. In 2003, Ulleberg [10] proposed a model based on thermodynamic concepts and heat transfer to obtain the voltage of the package, the gas flow produced and the thermal equilibrium of the system, all of them as a function of the imposed current. Later, Amores et al. [11] go deeper adding the electrolyte concentration and electrode distance as influencing parameters. Based on the same thermodynamic setup defining the ideal water dissociation voltage, Ursúa and Sanchis [12] built an electric model of over-voltages. Despite it is only limited to an electrical analysis, this work is among the few presenting dynamic equations. There are also more detailed models of the cell such as $[13,14]$. These works, among others, are compiled by Haug et al. [15] in their exhaustive mathematical representation of the cell that studies in depth the concept of gas contamination. This topic is analysed also by Roy in his doctoral thesis [16] that describes the dynamic behaviour of the cell.

Beyond the analysis of the electrolytic cell, according to Olivier et al. in their review of the literature [17], they do not find works on alkaline electrolysis that deal with the modelling of the complete system or fluid issues. In that sense, the "coupled multiphysic phenomena" are not totally cover in any model of the reported in that review. Sanchez et al [18] recently have proposed the use of commercial software to model the entire system using a semi-empirical approach for cell description only. However, this proposal focuses on the steady state.

Consequently, the main contribution of this paper is focused on developing a phenomenological-based semi-physical model (PBSM) according to previous models and our own experimental knowledge. Here, the processes occurring in the electrolyzer considering the entire system is described in terms of dynamic equations. This work continues the partial model reported in [19]. That preliminary model was developed only for the hydrogen side and with simplified assumptions for the interconnection of both sides. This current model will give a more accurate idea of the dynamics at high pressure operation and even provide guidelines for improvements in the design of new prototypes. In addition, the phenomenological-based approach facilitates the refinement of the model using better formulations in order to calculate model parameters. This experimentally-validated model is being used as a simulator 
and as a source for model reduction in order to design control strategies.

The remainder of the paper is structured as follows. In Section 2, the work methodology is explained and the final model is shown. In Section 3, the simulations are presented, analyzed and compared with the data taken from the real system. In the end, Section 4 presents the main conclusions of this work.

\section{Building of a PBSM of hydrogen production by water electrolysis}

The structure of a PBSM comes from conservation principles and takes advantage of empirical equations to evaluate model parameters. Then, a gray-box model is obtained from a combination of both white-box and black-box models [20, 21]. PBSM have four properties that make the difference regarding other type of models: i) uniqueness of the model basic structure since the balance equations obtained from applying the conservation law are the same for each processes family, ii) modularity due to the ability for expanding a PBSM from an initial model that considers only a part of the process to a model with additional parts of the same process, iii) the option of combining levels of detail with the possibility of modelling to as small scale as being required, and iv) parameter interpretability, i.e., most of the parameters of the model have a physical meaning within the process being modelled. The proposed methodology, deeply described in other works [22, 23] and used to model other processes $[24,25,26]$, is applied next to a particular electrolyzer.

\subsection{Process description and model objective}

Figure 1.(a) shows a schematic of the Electrolyzer of the Hydrogen Laboratory (ELH by its Spanish acronym). This prototype was designed and built by ITBA. Electrolyzers normally produce hydrogen with high purity, above 99\%. With highpressure alkaline electrolyzers this value goes down at higher pressures. Commercial electrolyzers handle pressures up to 30 bar. However, this prototype was designed up to 200 bar and was tested up to 70 bar. In that case, the purity of $\mathrm{O}_{2}$, which is always the lowest value, was $98 \%$. It has a pressurized tank containing a package of 15 alkaline electrolytic cells as illustrated in Figure 1.(b), two gas separation chambers, two refrigeration systems, two $\mathrm{KOH}$ solution circuits, and one water makeup pump. The symmetry of the assembly is used in the system modelling allowing a parallel implementation of the equations.

This high-pressure alkaline electrolyzer is an unstable system due to the production of gases that are collected in the Separation Chambers. Only under closed loop operation with the introduction of a system that controls the valves opening, a normal operation could be expected. In that case, the electrolyzer could produce hydrogen at desired amounts of pressure and temperature. Moreover, in case the electric current is constant, the electrolyzer response will reach a steady state.

As previously stated, to control the pressure of gases and levels in both chambers of the ELH, two motorized valves are installed in the gas outlet lines. The $\mathrm{KOH}$ concentration is variable due to the water production at the anode and its consumption at the cathode, as can be seen in Figure 1.(c). To avoid this variation, both circuits are communicated through the pressure tank in order to equalize their concentrations. Moreover, this line allows the equalization of the pressures inside and outside the cell. Dimensions of the piping and tanks are shown in Table 1. 


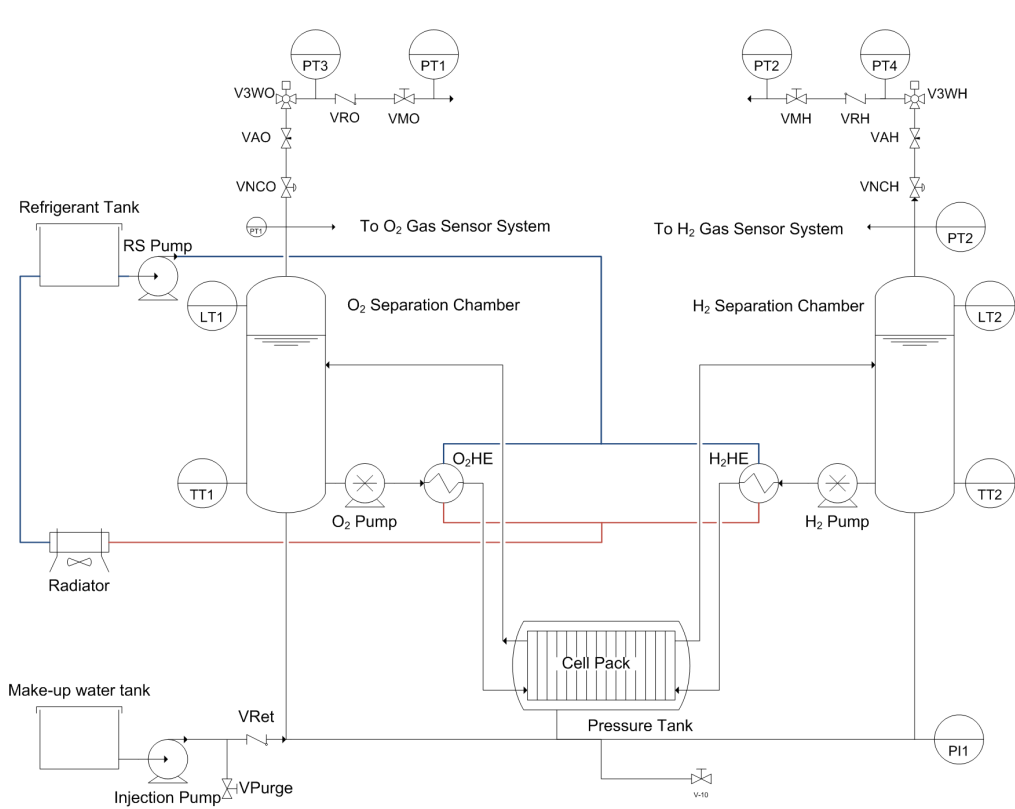

(a)

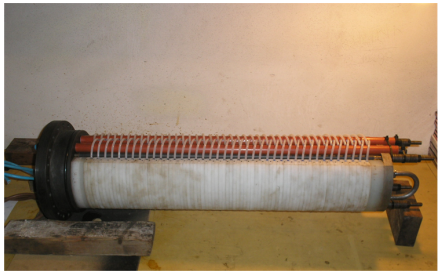

(b)

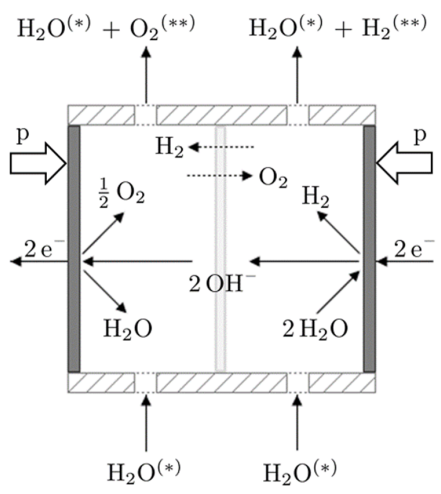

(c)

Figure 1: (a) Piping and instrumentation diagram of the ELH, (b) real cell package, and (c) scheme of the electrolytic cell with reactions. $\mathrm{H}_{2} \mathrm{O}^{(*)}$ represents $\mathrm{KOH}$ solution and $\mathrm{O}_{2}{ }^{(* *)}$ and $\mathrm{H}_{2}{ }^{(* *)}$ represent outputs that are contaminated with $\mathrm{H}_{2}$ and $\mathrm{O}_{2}$, respectively.

Table 1: Measured dimensions for piping sections and accessories

\begin{tabular}{lll}
\hline Accessory & $\begin{array}{l}\text { Length } \\
{[\mathrm{cm}]}\end{array}$ & Diameter $[\mathrm{cm}]$ \\
\hline \hline Straight sections I & 312 & 1.58 \\
Straight sections $\mathrm{II}^{2}$ & 244 & 1.58 \\
Annulus & 32 & $D_{\text {equiv }}=7.57$ \\
Cell $^{3}$ & 1.6 & 13.8 \\
Separation chamber $_{\text {Other accessories }}$ & 60 & 8.2 \\
\hline
\end{tabular}

${ }^{1}$ Identical circuit for the cathodic and anodic recirculation line $(13 \rightarrow 11$ and $14 \rightarrow 12)$. The numbering refers to Figure 2 .

${ }^{2}$ Equalization line $(7 / 8 \rightarrow 8 / 7)$.

3 Values for individual cell. Number of cells in the Package Cell $n_{\text {cell }}=15$.

The model objective is to predict $a$ ) the contamination of each gas stream with the other gas due to the membrane permeability and the diffusivity throught the equalization line and $b$ ) the changes in both pressure and levels in the separations chambers according to the current. The operation can be split in two major phenomena: the gas production at each half-cell and the gas separation and compression in the separation chambers. The relationship U-I is not developed in this system model due to the vast literature explaining it, as referred in Section 1. 


\subsection{Modelling hypothesis}

The cell pack is immerse in an alkaline solution, commonly with a $\mathrm{KOH}$ concentration between $25 \%$ and $30 \%$ (mass percent composition), which presents the highest conductivity. A KOH purity greater than $99 \%$ is recommended to avoid carbonate contamination. At each electrode of the electrolytic cell (Figure 1.(c)), the water reacts driven by the electric current under the following reactions:

$$
\begin{aligned}
2 \mathrm{H}_{2} \mathrm{O}+2 \mathrm{e}^{-} & \longrightarrow \mathrm{H}_{2}+2 \mathrm{OH}^{-}(\mathrm{aq}), \\
2 \mathrm{OH}^{-}(\mathrm{aq}) & \longrightarrow \frac{1}{2} \mathrm{O}_{2}+2 \mathrm{e}^{-}+\mathrm{H}_{2} \mathrm{O} .
\end{aligned}
$$

Each reaction in (1) occurs in a half cell, no direct mixing of gases is present. However, dissolved gases can permeate through the separation membrane by crosscontaminating both cells (first contamination focus). The solution with the produced gases is transported to the separation chamber (SC). All excess of gas over the solubility limit flows with the liquid as small bubbles. In these chambers, the separation of the gas bubbles that accumulate in the upper part is achieved. The gas-saturated solution, but without bubbles, is removed from the SC through the recirculation pump again towards the cell. A variable flow through the pressure equalization line is established due to physical laws. In addition, a constant diffusion of dissolved gases is imposed through this connection (second contamination focus).

The assumptions completing the modelling hypothesis previously stated are:

i) perfect agitation in all volumes, except gassed liquid in the separation chamber,

ii) the half cells always operate at full volume without gas accumulation,

iii) all the ion $\mathrm{OH}^{-}$is produced or consumed within the half cells, i.e., there is no $\mathrm{OH}^{-}$in any other stream,

iv) spatially uniform temperature throughout the device,

v) temporarily constant temperature due to the action of the cooling system,

vi) the recirculation pumps allow to overcome the friction in the system and guarantee the flow between the half cells and the separation chambers,

vii) the gas mixture in the upper part of the separation chambers is considered as an ideal gas, and

viii) gas as bubbles, produced in the half cells, are contaminated with dissolved impure gas only on the free surface of the liquid at the separation chamber.

\subsection{Process system definition}

In Figure 2, the construction of the model based on the definition of the process systems can be seen. A process system (PS) is defined as each volume of interest, taken as a system, where the analysis of the amounts of matter and energy is defined. The number of each PS is placed in Roman numbers next to each box. Although the 16 process systems that appear are drawn, it is not necessary to make balances 
on all, since most of them present a very simple action, which can be formulated with an algebraic expression. In addition, the symmetry of the processes (there are two half-circuits, one per each half-cell), facilitates the construction of the model. The following pairs of process systems are of interest and for them all balances must be raised (equal in their mathematical structure by symmetry, but with particular parameters): PSs I and II, PSs III and IV, PSs IX and X, and finally, PS XIII, which does not have symmetry. No balance is calculated for the other PSs because they have trivial models, as mentioned. For convenience, all balances are presented on a molar basis. The sign convention for any PS indicates a positive $+\dot{n}_{i}$ for an inflow and negative $-\dot{n}_{i}$ for an outflow.

In Section 2.4, the most representative PSs are explained along with the conservation principle application. Taking advantage of the problem symmetry, balances are raised for PSs I, III, XI and XIII.

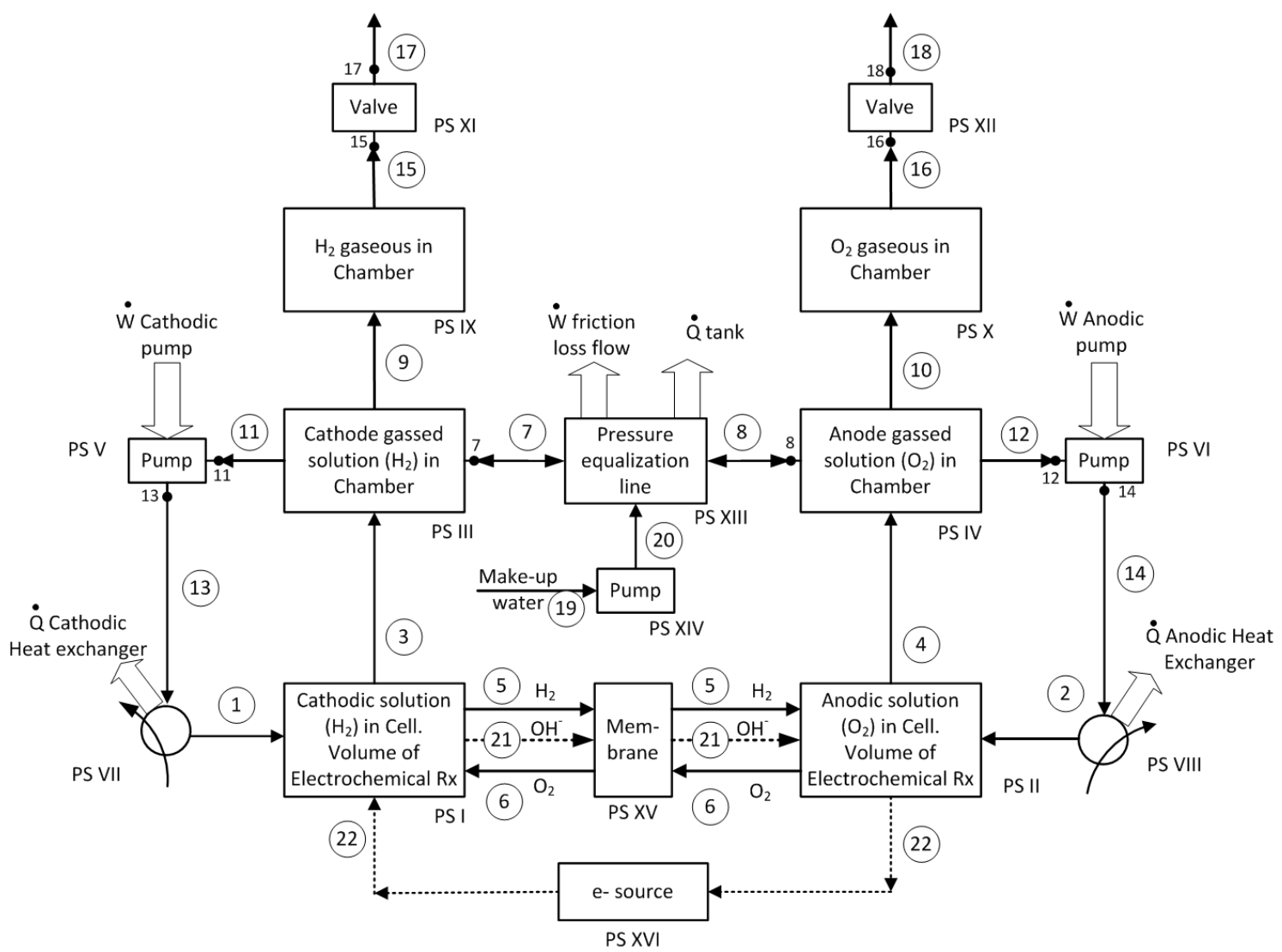

Figure 2: Flow diagram with the PSs numbered in Roman. Mass flows are identified with numbers within circles

\subsection{Application of the conservation principle}

Based on the analysis performed in Section 2.3, the conservation law will be applied to each PS of interest. First, to illustrate the procedure, the Total Material Balance (TMB) and the Component Material Balance (CMB) for $\mathrm{H}_{2}$ in the PS I are described. Next, details for PSs III, XI and XIII are shown in order to explain the most important phenomena that occur during the process operation. Later, 
in Section 2.5, the complete set of balances is presented. In that sense, the basic modelling structure is obtained, fulfilling the model objectives set in Section 2.1.

\subsubsection{PS I - Cathodic solution in cell}

This PS has the same structure of equations as PS II, as previously mentioned. Due to the similarity, only the component mass balance for hydrogen is presented.

Total Material Balance. Based on Figure 2, the global balance is obtained as

$$
\frac{d N_{I}}{d t}=\dot{n}_{1}+\dot{n}_{6}-\dot{n}_{21}-\dot{n}_{3}-\dot{n}_{5}+\dot{n}_{22}+r_{1} \sum_{i} \sigma_{i, 1},
$$

being $N_{I}$ the total number of moles in the anodic half cell, $\dot{n}_{j}$ the $j$-th flow as labeled in Figure 2, and $r_{1}$ the speed of the half-cell electrochemical reaction (1). Finally, each $\sigma_{i, 1}$ is the stoichiometric coefficients of species $i$ in the same reaction.

The total number of moles can be expressed as $N_{I}=\bar{\rho} V_{\text {mix }, I}$, where $\bar{\rho}$ is the molar density of the mixture in $\frac{\mathrm{kmol}}{\mathrm{m}^{3}}$ and $V_{\text {mix }, I}$ is the volume of the entire mixture (liquid and gas bubbles) contained in the PS I. With the assumption of constant volume of the half cell, applying the derivative to replace it in (2) and considering that the molar flow of electrons is equal to the molar flow of $\mathrm{OH}^{-}$, the final balance equation is as follows:

$$
\frac{d \bar{\rho}_{3}}{d t}=\frac{1}{V_{m i x, I}}\left[\dot{n}_{1}+\dot{n}_{6}-\dot{n}_{3}-\dot{n}_{5}+r_{1} \sum_{i} \sigma_{i, 1}\right] .
$$

Component Material Balance. The balance for $\mathrm{H}_{2}$ in PS I is

$$
\frac{d N_{\mathrm{H}_{2}, I}}{d t}=x_{\mathrm{H}_{2}, 1} \dot{n}_{1}+x_{\mathrm{H}_{2}, 6} \dot{n}_{6}-x_{\mathrm{H}_{2}, 21} \dot{n}_{21}-x_{\mathrm{H}_{2}, 3} \dot{n}_{3}-x_{\mathrm{H}_{2}, 5} \dot{n}_{5}+r_{1} \sigma_{\mathrm{H}_{2}, 1},
$$

where $N_{\mathrm{H} 2, I}$ is the moles of hydrogen contained in the PS I and $x_{\mathrm{H}_{2}, j}$ is the molar fraction of $\mathrm{H}_{2}$ with respect to the $j$-th flow. It should be clarified that $x_{\mathrm{H}_{2}, j}$ for stream 3 and eventually for stream 1, if the separation chamber is not operating correctly, refers to both dissolved and bubble hydrogen. Moreover, it is considered that the $\mathrm{H}_{2}$ concentrations in streams 6 and 21 are zero, i.e., $x_{\mathrm{H}_{2}, 6}=x_{\mathrm{H}_{2}, 21}=0$, that the stoichiometric coefficient $\sigma_{\mathrm{H}_{2}, 1}=1$ and that the outgoing flow that passes through the membrane $\dot{n}_{5}$ is composed only of $\mathrm{H}_{2}$. Finally, knowing that $N_{\mathrm{H}_{2}, I}=$ $x_{\mathrm{H}_{2}, I} N_{I}$, the CMB equation is

$$
\frac{d x_{\mathrm{H}_{2}, 3}}{d t}=\frac{1}{N_{I}}\left[x_{\mathrm{H}_{2}, 1} \dot{n}_{1}-x_{\mathrm{H}_{2}, 3} \dot{n}_{3}-\dot{n}_{5}+r_{1}-x_{\mathrm{H}_{2}, 3} \dot{N}_{I}\right],
$$

where, by perfect agitation hypothesis, the concentration of output flow 3 can be considered equal to the compositions into this PS I.

\subsubsection{PS III - Cathode gassed solution in $\mathrm{H}_{2}$ Chamber}

The analysis performed for this PS includes the molar and volume balance developed below. It is recalled that this PS is similar to PS IV. 
Total Material Balance. This balance, expressed on molar basis, is

$$
\frac{d N_{I I I}}{d t}=\dot{n}_{3}-\dot{n}_{7}-\dot{n}_{9}-\dot{n}_{11}
$$

where molar flow $\dot{n}_{3}$ is calculated in the $\mathrm{PS}_{I}$, and the flows $\dot{n}_{7}$ and $\dot{n}_{11}$ from the mechanical energy balances in the line of equalization of pressures (PS XIII) and in the pump (PS V), respectively. The molar flow corresponding to the output $\dot{n}_{9}$ will be modeled as the gradual separation of the bubbles present in the liquid with a time constant to be adjusted, i.e.,

$$
\dot{n}_{\mathrm{H}_{2}, 9}=\frac{N_{\mathrm{H}_{2}, b}}{\tau_{b}},
$$

which represents the flow of hydrogen and will be the same mathematical for oxygen. The moles of hydrogen as bubbles in the separation chamber, $N_{\mathrm{H} 2, b}$, are described in (21).

Total Volume Balance. Taking into account that the volume variation is equal to the variation of level by the constant section of separation chamber, it yields

$$
\frac{d L_{L g, I I I}}{d t}=\frac{1}{A_{S C}}\left(\dot{V}_{3}-\dot{V}_{7}-\dot{V}_{9}-\dot{V}_{11}+\dot{V}_{b, I I I}\right),
$$

where $L_{L g}$ is the level of gassed liquid in the SC. All volumetric flows $\dot{V}_{j}$ are related to the molar flow and their densities. Likewise, the term $\dot{V}_{b, I I I}$ represents the effects of a volumetric change of bubbles, e.g., the violent depressurization that occur due to the rapid opening of valves. This parameter will be further analyzed in Section 2.6.1.

Component Material Balance. Hydrogen balance will be developed here highlighting that it will have the same form as the $\mathrm{O}_{2}$. The variation of moles of $\mathrm{H}_{2}$ in the separation chamber can be calculated as

$$
\frac{d N_{\mathrm{H}_{2}, I I I}}{d t}=x_{\mathrm{H}_{2}, 3} \dot{n}_{3}-x_{\mathrm{H}_{2}, 7} \dot{n}_{7}-\dot{n}_{\mathrm{H}_{2}, 9}-x_{\mathrm{H}_{2}, 11} \dot{n}_{11} .
$$

Knowing that $N_{\mathrm{H}_{2}, I I I}=x_{\mathrm{H}_{2}, I I I} N_{I I I}$ and taking the time derivative yields

$$
\frac{d x_{\mathrm{H}_{2}, I I I}}{d t}=\frac{1}{N_{I I I}}\left(x_{\mathrm{H}_{2}, 3} \dot{n}_{3}-x_{\mathrm{H}_{2}, 7} \dot{n}_{7}-x_{\mathrm{H}_{2}, 9} \dot{n}_{9}-x_{\mathrm{H}_{2}, 11} \dot{n}_{11}-x_{\mathrm{H}_{2}, I I I} \dot{N}_{I I I}\right) .
$$

It is noted here that the molar concentration in (10) is different to all the inputs and outputs of this PS and denotes the $\mathrm{H}_{2}$ contained in both the dissolved gas and the bubbles.

\subsubsection{PS XI - Cathodic output valve}

As initially commented, this PS has the same structure of equations as the PS XII. 
Total Material Balance. For the valve, this balance on molar basis is

$$
\frac{d N_{X I}}{d t}=\dot{n}_{15}-\dot{n}_{17}
$$

Since it can be considered that the moles inside the valve are quite few and remain constant, the trivial equation that relates the outgoing flow of the separation chamber with the output of the ELH is obtained as

$$
\dot{n}_{15}=\dot{n}_{17} .
$$

Mechanical Energy Balance (MEB). Following the analysis for this PS, the mechanical energy balance is

$$
0=g\left(z_{17}-z_{15}\right)+\frac{P_{17}-P_{15}}{\rho_{g}}+\frac{v_{17}^{2}-v_{15}^{2}}{2}+h_{f, 15 \rightarrow 17},
$$

where $z_{15}$ y $z_{17}, P_{15}$ y $P_{17}$, y $v_{15}$ y $v_{17}$ are the relative heights, pressures, and velocities of inlet and outlet, respectively, while $h_{f, 15 \rightarrow 17}$ are the friction losses caused by the flow through the valve. The heights $z_{15}$ and $z_{17}$ are considered equal and the variation of specific kinetic energy is null since $v_{15}=v_{17}$. Using the known expression for the volumetric flow $\left(\dot{V}_{17}\right)$ that passes through the valve, the typical formulation for calculating the friction losses $h_{f, 15 \rightarrow 17}$ provides the gas velocity in the line. Therefore

$$
\dot{V}_{17}=C_{v, 1} u_{1} \sqrt{\frac{P_{17}-P_{15}}{\rho_{g, X I}}},
$$

being the definition of the parameter $C_{v}$ generally informed by the valve manufacturer and defining $u_{1}$ as the control variable (opening ratio). In this case the term $C_{v} u_{1}$ is rewritten as a function $f_{\text {out }, \mathrm{H} 2}$, which is a polynomial function of order 5 that adjusts the available information on valve operation. Finally,

$$
\dot{V}_{17}=f_{\text {out }, \mathrm{H}_{2}}\left(u_{1}\right) \sqrt{\frac{P_{17}-P_{15}}{\rho_{g, X I}}} .
$$

\subsubsection{PS XIII - Pressure equalization line}

This line links both gas separation chambers.

Total Material Balance. First, the total material balance in the pressure equalization line will be developed, assuming that the make-up pump is on only for a few seconds every six hours of operation (this time is relative to the water consumption, i.e. electrical current). In that case, the balance is

$$
\frac{d N_{X I I I}}{d t}=\dot{n}_{8}-\dot{n}_{7}=0 \Rightarrow \dot{n}_{8}=\dot{n}_{7} .
$$

It should be highlighted that the signs $+\dot{n}_{7}$ and $-\dot{n}_{8}$ mean that flow goes from the anode chamber (PS IV) to the cathode chamber (PS III). In case flow goes in the opposite direction, these signs are $-\dot{n}_{7}$ and $+\dot{n}_{8}$. This special situation, which differs from the general convention mentioned in Section 2.3, is taken into account when the material balance at each separation chamber is defined. 
Mechanical Energy Balance. Following the analysis for this PS, the mechanical energy balance from points 8 to 7 is

$$
0=g\left(z_{8}-z_{7}\right)+\frac{P_{8}-P_{7}}{\rho_{S \ln \mathrm{KOH}}}+\frac{v_{8}^{2}-v_{7}^{2}}{2}+h_{f, 8 \rightarrow 7},
$$

being $z_{8}$ and $z_{7}, P_{8}$ and $P_{7}$, and $v_{8}$ and $v_{7}$ the heights, pressures and velocity of entry and exit, respectively. Finally, the friction losses caused by the flow through the equalization pressure line between 8 and 7 are defined as $h_{f, 8 \rightarrow 7}$. Considering negligible the change of velocity between inlet and outlet when the steady state is reached, the MEB for this PS is expressed as

$$
h_{f, 8 \rightarrow 7}=f\left(\dot{m}_{8}\right)=g\left(z_{7}-z_{8}\right)+\frac{P_{7}-P_{8}}{\rho_{S l n \mathrm{KOH}}} .
$$

It is recalled that the friction losses between 7 and 8 are a function of the Reynolds number in the different line sections and accessories, which at the same time is a function of the mass flow that is circulating.

At this point, it is necessary to state that the instantaneous establishment of the flow is not fulfilled in any piping system. A sudden difference in separation chambers pressure is not immediately converted into flow change between points 7 and 8 , as it could be expected. The friction of the fluid during its flow and the elasticity of liquid filling the line impose a delay to any sudden flow change. To represent these phenomena, an adjustment of previous balance is needed. The mass flow calculated in (18) will be labeled as the theoretical mass flow $\dot{m}_{\text {theo }}$ and a capacitance model will be adopted for the calculation of real molar flows $\dot{n}_{7}$ and $\dot{n}_{8}$, as follows:

$$
\frac{d \dot{n}_{i}}{d t}=\frac{1}{\tau}\left(\frac{\dot{m}_{\text {theo }}}{\mathfrak{M}_{i}}-\dot{n}_{i}\right),
$$

where response time $\tau$ will be identified from data.

\subsection{Structure, parameters and constants}

After checking all the balance equations obtained in the previous step, the basic structure of the model is reported in Table 2. Those balance equations providing information that answer the questions asked to the model, are maintained in the model basic structure. Moreover, in Table 3 the nomenclature used for the variables, parameters and constants belonging to this model are presented, while Table 4 is used to show the degrees of freedom evaluation.

\subsection{Constitutive and assessment equations}

For each of the structural parameters, those that appear in the basic model structure, its constitutive or assessment equation is proposed in Table 5. After that, the equations for the new parameters that arise from the previous equations, which are called functional parameters, are summarized in Table 6. Finally, model constants considered are presented in Table 7. Those constitutive and assessment equations that are considered relevant to clarify, are explained below. 
Table 2: Balance equations forming the model basic structure.

\begin{tabular}{|c|c|c|}
\hline$\#$ & Equation & $\begin{array}{l}\text { Process } \\
\text { System }\end{array}$ \\
\hline 1 & $\frac{d \bar{\rho}_{3}}{d t}=\frac{1}{V_{m i x, I}}\left[\dot{n}_{1}+\dot{n}_{6}-\dot{n}_{3}-\dot{n}_{5}+r_{1} \sum_{i} \sigma_{i, 1}\right]$ & $S P_{I}$ \\
\hline 2 & $\frac{d x_{\mathrm{H} 2,3}}{d t}=\frac{1}{N_{I}}\left[x_{\mathrm{H}_{2}, 1} \dot{n}_{1}-x_{\mathrm{H}_{2}, 3} \dot{n}_{3}-\dot{n}_{5}+r_{1}-x_{\mathrm{H}_{2}, 3} \dot{N}_{I}\right]$ & $S P_{I}$ \\
\hline 3 & $\frac{d x_{\mathrm{O} 2,3}}{d t}=\frac{1}{N_{I}}\left[x_{\mathrm{O} 2,1} \dot{n}_{1}+\dot{n}_{6}-x_{\mathrm{O} 2,3} \dot{n}_{3}-x_{\mathrm{O} 2,3} \dot{N}_{I}\right]$ & $S P_{I}$ \\
\hline 4 & $\dot{n}_{21}=2 r_{1}$ & $S P_{I}$ \\
\hline 5 & $\dot{n}_{22}=2 r_{1}$ & $S P_{I}$ \\
\hline 6 & $\frac{d N_{I I I}}{d t}=\dot{n}_{3}+\dot{n}_{7}-\dot{n}_{9}-\dot{n}_{11}$ & $S P_{I I I}$ \\
\hline 7 & $\frac{d L_{L g, I I I}}{d t}=\frac{1}{A_{S C}}\left(\dot{V}_{3}-\dot{V}_{7}-\dot{V}_{9}-\dot{V}_{11}+\dot{V}_{\text {bubbles }}\right)$ & $S P_{I I I}$ \\
\hline 8 & $\frac{d x_{\mathrm{H} 2, I I I}}{d t}=\frac{1}{N_{I I I}}\left[x_{\mathrm{H}_{2}, 3} \dot{n}_{3}+x_{\mathrm{H}_{2}, 7} \dot{n}_{7}-\dot{n}_{\mathrm{H}_{2}, 9}-x_{\mathrm{H}_{2}, 11} \dot{n}_{11}-x_{\mathrm{H}_{2}, I I I} \dot{N}_{I I I}\right]$ & $S P_{I I I}$ \\
\hline 9 & $\frac{d x_{\mathrm{O} 2, I I I}}{d t}=\frac{1}{N_{I I I}}\left[x_{\mathrm{O}_{2}, 3} \dot{n}_{3}+x_{\mathrm{O}_{2}, 7} \dot{n}_{7}-\dot{n}_{\mathrm{O}_{2}, 9}-x_{\mathrm{O}_{2}, 11} \dot{n}_{11}-x_{\mathrm{O}_{2}, I I I} \dot{N}_{I I I}\right]$ & $S P_{I I I}$ \\
\hline 10 & $\dot{n}_{11}=\dot{n}_{13}$ & $S P_{V}$ \\
\hline 11 & $0=\eta_{1} \hat{W}_{1}-\frac{P_{13}-P_{11}}{\rho_{L, 11}} \Rightarrow f\left(\dot{m}_{13}\right)=h_{f, 13 \rightarrow 11}$ & $S P_{V}$ \\
\hline 12 & $x_{\mathrm{H}_{2}, 13}=x_{\mathrm{H}_{2}, 11}$ & $S P_{V}$ \\
\hline 13 & $x_{\mathrm{O}_{2,13}}=x_{\mathrm{O}_{2}, 11}$ & $S P_{V}$ \\
\hline 14 & $x_{\mathrm{H}_{2}, 1}=x_{\mathrm{H}_{2}, 13}$ & $S P_{V I I}$ \\
\hline 15 & $x_{\mathrm{O}_{2}, 1}=x_{\mathrm{O}_{2}, 13}$ & $S P_{V I I}$ \\
\hline 16 & $\frac{d P_{15}}{d t}=\frac{R T}{A_{T} L_{g, I X}}\left(\dot{n}_{9}-\dot{n}_{15}\right)-\frac{P_{15}}{L_{g, I X}} \dot{L}_{g, I X}$ & $S P_{I X}$ \\
\hline 17 & $\frac{d x_{\mathrm{H} 2,15}}{d t}=\frac{1}{N_{I X}}\left[x_{\mathrm{H}_{2}, 9} \dot{n}_{9}-x_{\mathrm{H}_{2}, 15} \dot{n}_{15}-x_{\mathrm{H}_{2}, 15} \dot{N}_{I X}\right]$ & $S P_{I X}$ \\
\hline 18 & $\frac{d x_{\mathrm{O} 2,15}}{d t}=\frac{1}{N_{I X}}\left[x_{\mathrm{O}_{2}, 9} \dot{n}_{9}-x_{\mathrm{O}_{2}, 15} \dot{n}_{15}-x_{\mathrm{O}_{2}, 15} \dot{N}_{I X}\right]$ & $S P_{I X}$ \\
\hline 19 & $\dot{n}_{15}=\dot{n}_{17}$ & $S P_{X I}$ \\
\hline 20 & $\dot{V}_{17}=f_{\text {out }, \mathrm{H}_{2}}\left(u_{1}\right) \sqrt{\frac{P_{17}-P_{15}}{\rho_{g, X I}}}$ & $S P_{X I}$ \\
\hline $\begin{array}{l}21 \\
22\end{array}$ & $\begin{array}{l}\frac{d N_{X I I I}}{d t}=\dot{n}_{X I I I, \text { in }}-\dot{n}_{X I I I, \text { out }}+\dot{n}_{20} \\
0=\frac{P_{8}-P_{7}}{\rho_{L}}-h_{f, 8 \rightarrow 7} \Rightarrow f\left(\dot{m}_{8}\right)=\frac{P_{8}-P_{7}}{\rho_{L}}\end{array}$ & $\begin{array}{l}S P_{X I I I} \\
S P_{X I I I}\end{array}$ \\
\hline 23 & $\begin{array}{l}\frac{d x_{\mathrm{H} 2, X I I I}}{d t}=\frac{1}{N_{X I I I}}\left[x_{\mathrm{H}_{2}, X I I I, \text { in }} \dot{n}_{X I I I, \text { in }}-x_{\mathrm{H}_{2}, X I I I, \text { out }} \dot{n}_{X I I I, \text { out }}+\right. \\
\left.A_{\text {line }} \Phi_{\mathrm{H}_{2}}-x_{\mathrm{H}_{2}, X I I I} \dot{N}_{X I I I}\right]\end{array}$ & $S P_{X I I I}$ \\
\hline 24 & $\begin{array}{l}\frac{d x_{\mathrm{O} 2, X I I I}}{d t}=\frac{1}{N_{X I I I}}\left[x_{\mathrm{O} 2, X I I I, \text { in }} \dot{n}_{X I I I, \text { in }}-x_{\mathrm{O}_{2}, X I I I, \text { out }} \dot{n}_{X I I I, \text { out }}+\right. \\
\left.A_{\text {line }} \Phi_{\mathrm{O}_{2}}-x_{\mathrm{O}_{2}, X I I I} \dot{N}_{X I I I}\right]\end{array}$ & $S P_{X I I I}$ \\
\hline
\end{tabular}

\subsubsection{Volume change in $S C$}

Previously, the concept of volume change due to the gas that passes from solution to bubbles in (8) was incorporated. At the time instants when the pressure changes drastically, the solubility of the aqueous solution also changes, releasing a consid- 
Table 3: List of symbols

\begin{tabular}{|c|c|c|c|}
\hline $\begin{array}{l}\text { Sym- } \\
\text { bol }\end{array}$ & Name & Symbol & Name \\
\hline $\bar{\rho}_{i}$ & Molar density of stream $i$ & $V_{m i x, N}$ & Volume in process system $N$ \\
\hline$\dot{n}_{i}$ & Molar flow in stream $i$ & $r_{z}$ & Reaction speed of reaction $z$ \\
\hline$I$ & Electrical input current & $\sigma_{K, z}$ & $\begin{array}{l}\text { Stoichiometric coefficient of } K \text { in } \\
\text { reaction } z\end{array}$ \\
\hline$x_{K, i}$ & $\begin{array}{l}\text { Concentration of species } K \text { in } \\
\text { molar fraction in stream } i\end{array}$ & $N_{N}$ & Total moles in process system $N$ \\
\hline$M_{N}$ & Total mass in process system $N$ & $\dot{m}_{i}$ & Mass flow in stream $i$ \\
\hline$w_{K, i}$ & $\begin{array}{l}\text { Concentration of species } K \text { in } \\
\text { mass fraction in stream } i\end{array}$ & $\eta_{z}$ & $\begin{array}{l}\text { Cathodic/anodic pump effi- } \\
\text { ciency }\end{array}$ \\
\hline$\hat{W}_{z}$ & $\begin{array}{l}\text { Specific work of the Ca- } \\
\text { thodic/anodic pump }\end{array}$ & $P_{j}$ & Pressure in point $\mathrm{j}$ \\
\hline$\rho_{L, i}$ & Mass density in stream $i$ & $R$ & Ideal gas constant \\
\hline$T$ & System temperature & $\mathfrak{M}_{K}$ & Molar mass of species $\mathrm{K}$ \\
\hline$A_{S C}$ & Separation chamber cross area & $L_{g, N}$ & $\begin{array}{l}\text { Height of gas volume in process } \\
\text { system } N\end{array}$ \\
\hline$\rho_{g, N}$ & $\begin{array}{l}\text { Mass density of gas in process } \\
\text { system } N\end{array}$ & $\dot{V}_{i}$ & Volumetric flow in stream $i$ \\
\hline$h_{f, a \rightarrow b}$ & Friction energy loss from $a$ to $b$ & $\epsilon$ & Absolute pipe roughness \\
\hline
\end{tabular}

Table 4: Variables, parameters and constants of the model.

\begin{tabular}{|c|c|c|}
\hline & Instance & Total \\
\hline Variables & $\begin{array}{l}\bar{\rho}_{3}, x_{\mathrm{H}_{2}, 3}, x_{\mathrm{O}_{2}, 3}, n_{21}, n_{22}, \bar{\rho}_{4}, x_{\mathrm{O}_{2}, 4}, x_{\mathrm{H}_{2}, 4}, M_{I I I}, L_{L g, I I I}, N_{I V} \\
L_{L g, I V}, n_{13}, n_{11}, x_{\mathrm{H}_{2}, 13}, x_{\mathrm{O}_{2}, 13}, n_{14}, n_{12}, x_{\mathrm{O}_{2}, 14}, x_{\mathrm{H}_{2}, 14}, n_{1}, \\
x_{\mathrm{H}_{2}, 1}, x_{\mathrm{O}_{2}, 1}, n_{2}, x_{\mathrm{O}_{2}, 2}, x_{\mathrm{H}_{2}, 2}, P_{15}, x_{\mathrm{H}_{2}, 15}, x_{\mathrm{O}_{2}, 15}, P_{16}, x_{\mathrm{O}_{2}, 16} \\
x_{\mathrm{H}_{2}, 16}, n_{15}, n_{17}, n_{16}, n_{18}, n_{7}, n_{8}\end{array}$ & 38 \\
\hline Parameters & $\begin{array}{l}\dot{n}_{i}, \quad \dot{V}_{i}, \dot{m}_{i}, \Phi_{X-Y, \text { Fick }}, C_{X, 3 / 4}, C_{X, s a t, I / I I}, \Phi_{X-Y, \text { Darcy }}, \\
r, \quad \eta_{F}, \quad N_{I / I I}, \eta_{\text {pump }, j}, \hat{W}_{\text {pump }, j}, h_{f, a \rightarrow b}, x_{X, 9 / 10}, x_{X(g), 3 / 4}, \\
w_{\mathrm{H}_{2} \mathrm{O}, 11 / 12}, x_{X, 11 / 12}, T, L_{g, I X / X}, \dot{L}_{g, I X / X}, N_{I / I I}, \dot{N}_{I / I I}, \\
\rho_{g, X I / X I I}\end{array}$ & 93 \\
\hline $\begin{array}{l}\text { Structural } \\
\text { Constants }\end{array}$ & $\begin{array}{l}\sigma_{X, r_{j}}, R, \mathfrak{M}_{X}, \rho_{X}, K_{H e, X}, D_{X}, \text { perm }_{X}, A_{\text {cell }}, n_{\text {cell }}, z_{c e l l}, \\
V_{\text {mix }, i}, A_{S C}, L_{S C}\end{array}$ & 30 \\
\hline
\end{tabular}

erable amount of gas in the form of bubbles, which is called sudden gasification. Considering the ideal gas law and recalling the constant temperature hypothesis, the expression to calculate this volumetric change of bubbles is expressed as follows:

$$
\dot{V}_{b, I I I}=\dot{n}_{b, I I I} \frac{R T}{P_{I X}}-\frac{n_{b, I I I} R T}{P_{I X}^{2}} \dot{P}_{I X},
$$

where $\dot{n}_{b}$ is the migration of dissolved gas to bubbles and vice versa. The amount of gas present in the gassed solution will be the sum of the $\mathrm{H}_{2}$ and $\mathrm{O}_{2}$ bubbles, ( $n_{\mathrm{H}_{2}, b, I I I}$ and $n_{\mathrm{O}_{2}, b, I I I}$, respectively). Analyzing only hydrogen, for example, and computing the time derivative, the moles of hydrogen are obtained as

$$
n_{\mathrm{H}_{2}, b, I I I}=\left(x_{\mathrm{H}_{2}, I I I}-x_{\mathrm{H}_{2}, s a t}\right) N_{I I I},
$$

and the molar flow of hydrogen produced by the bubbles is 
Table 5: Constitutive and assessment equations for structural parameters

\begin{tabular}{|c|c|c|}
\hline$\#$ & Parameter & Equation \\
\hline 1 & $\dot{n}_{n}$ & $\dot{n}_{n}=\dot{V}_{n} \bar{\rho}_{n}$ \\
\hline 3 & $\dot{n}_{5}$ & $\dot{n}_{5}=\left(\Phi_{\mathrm{H}_{2}-\mathrm{O}_{2}, \text { Fick }}+\Phi_{\mathrm{H}_{2}-\mathrm{O}_{2}, \text { Darcy }}\right) A_{\text {cell }} n_{\text {cell }}$ \\
\hline 4 & $\dot{n}_{6}$ & $\dot{n}_{6}=\left(\Phi_{\mathrm{O}_{2}-\mathrm{H}_{2}, \text { Fick }}+\Phi_{\mathrm{O}_{2}-\mathrm{H}_{2}, \text { Darcy }}\right) A_{\text {cell }} n_{\text {cell }}$ \\
\hline 5 & $r$ & $r=\eta_{F} \frac{n_{c e l l}}{\sigma_{\mathrm{e}^{-}, 2} F} I$ \\
\hline 6 & $N_{M}$ & $N_{M}=V_{m i x, M} \bar{\rho}_{m}$ \\
\hline 8 & $\dot{N}_{M}$ & $\dot{N}_{M}=V_{m i x, M} \dot{\bar{\rho}}_{m}$ \\
\hline 10 & $\dot{n}_{q}$ & $\dot{n}_{q}=\left(n_{\mathrm{H}_{2}, N, b}+n_{\mathrm{O}_{2}, N, b}\right) \frac{F C_{f l a s h}}{\tau_{b}}$ \\
\hline 12 & $\dot{n}_{r}$ & $\dot{n}_{r}=\frac{\dot{m}_{r}}{\mathfrak{M}_{r}}$ \\
\hline 14 & $\dot{V}_{3}$ & $\dot{V}_{3}=\dot{V}_{1}+\dot{V}_{\mathrm{H}_{2}, r_{1}}-\dot{V}_{\mathrm{H}_{2} \mathrm{O}, r_{1}}-\dot{V}_{5}+\dot{V}_{6}$ \\
\hline 15 & $\dot{V}_{p}$ & $\dot{V}_{p}=\frac{\dot{m}_{p}}{\rho_{S \ln K O H}}$ \\
\hline 17 & $\dot{V}_{q}$ & $\dot{V}_{q}=\dot{n}_{q} \frac{R T}{P_{M}}$ \\
\hline 19 & $\dot{V}_{r}$ & $\dot{V}_{r}=\dot{m}_{r} \frac{w_{\mathrm{H} 2 \mathrm{O}, r}}{\rho_{\operatorname{Sln} K O H}}$ \\
\hline 21 & $\dot{V}_{b, N}$ & $\dot{V}_{b, N}=-\left(n_{\mathrm{H}_{2}, N, b}+n_{\mathrm{O}_{2}, N, b}\right) R T \frac{\dot{P}_{Q}}{P_{Q}{ }^{2}}$ \\
\hline 23 & $x_{D, p}$ & $x_{D, p}=\min \left(x_{D, n}, x_{D, s a t, M}\right)$ \\
\hline 27 & $x_{D, q}$ & $x_{D, q}=\frac{n_{D, N, b}}{n_{\mathrm{H} 2, N, b}+n_{\mathrm{O} 2, N, b}}$ \\
\hline 31 & $x_{D, r}$ & $x_{D, r}=\min \left(x_{D, n}, x_{D, s a t, M}\right)$ \\
\hline 35 & $\dot{V}_{4}$ & $\dot{V}_{4}=\dot{V}_{2}+\dot{V}_{\mathrm{O}_{2}, r}+\dot{V}_{\mathrm{H}_{2} \mathrm{O}, r_{2}}+\dot{V}_{5}-\dot{V}_{6}$ \\
\hline 36 & $h_{f, a \rightarrow b}$ & $h_{f, a \rightarrow b}=\sum_{S}\left(K_{S} \frac{v_{S}^{2}}{2}\right)$ \\
\hline 39 & $L_{g, Q}$ & $L_{g, Q}=L_{S C}-L_{L g, N}$ \\
\hline 41 & $\dot{L}_{g, Q}$ & $\dot{L}_{g, Q}=-\frac{d L_{L g, N}}{d t}$ \\
\hline 43 & $N_{Q}$ & $N_{Q}=\frac{P_{Q} A_{S C} L_{g, Q}}{R T}$ \\
\hline 45 & $\dot{N}_{Q}$ & $\dot{N}_{Q}=\dot{n}_{q}-\dot{n}_{t}$ \\
\hline 47 & $\dot{m}_{\text {theo }}$ & $f\left(\dot{m}_{\text {theo }}\right)=h_{f, 7 \rightarrow 8}\left(\dot{m}_{\text {theo }}\right)+g\left(L_{g, I I I}-L_{g, I V}\right)+\frac{P_{15}-P_{16}}{\rho_{\text {SInKOH }}}$ \\
\hline
\end{tabular}

Indexes: $a \rightarrow b$ : flow from point $a$ to $b, D: \mathrm{H}_{2}$ or $\mathrm{O}_{2}, m$ : flows 1 or $2, n$ : flows 3 or $4, p$ : flows 7 or $8, q$ : flows 9 or $10, r$ : flows 11 or 12 , $t$ : flows 15 or $16, M$ : PSs I or II, $N$ : PSs III or IV, $Q$ : PSs IX or X,

$$
\dot{n}_{\mathrm{H}_{2}, b}=\left(x_{\mathrm{H}_{2}, I I I}-x_{\mathrm{H}_{2}, s a t}\right) \dot{N}_{I I I}+\left(\frac{d x_{\mathrm{H}_{2}, I I I}}{d t}-\dot{x}_{\mathrm{H}_{2}, s a t}\right) N_{I I I}
$$

At this point, the unknown term that remains is $\dot{x}_{\mathrm{H}_{2}, \text { sat }}$. Defining the saturation concentration from Henry's law [31] and taking the time derivative of it, it yields

$$
\frac{d x_{\mathrm{H}_{2}, s a t}}{d t}=x_{\mathrm{H}_{2}, s a t}\left(\frac{\dot{x}_{\mathrm{H}_{2}, 15}}{x_{\mathrm{H}_{2}, 15}}+\frac{\dot{P}_{I X}}{P_{I X}}-\frac{\dot{N}_{I I I}}{N_{I I I}}+\frac{\dot{L}_{L g, I I I}}{L_{L g, I I I}}\right),
$$


Table 6: Constitutive and assessment equations for functional parameters

\begin{tabular}{|c|c|c|}
\hline \# & Parameter & Equation \\
\hline 1 & $\Phi_{D-E, F i c k}$ & $\Phi_{D-E, F i c k}=D_{D} \frac{C_{D, n_{D}}-C_{D, n_{E}}}{z_{\text {cell }}}$ \\
\hline 3 & $C_{D, n}$ & $C_{D, n}=\min \left(x_{D, n} \bar{\rho}_{n}, C_{D, s a t, M}\right)$ \\
\hline 7 & $C_{D, s a t, M}$ & $C_{D, s a t, M}=K_{H e, D} x_{D, n} P_{N}$ \\
\hline 11 & $\Phi_{D-E, \text { Darcy }}$ & $\Phi_{D-E, \text { Darcy }}=\epsilon_{D}^{\text {Darcy }} \frac{P_{N_{D}}-P_{N_{E}}}{z_{\text {cell }}}$ \\
\hline 13 & $n_{D, N, b}$ & $n_{D, N, b}=\max \left(x_{D, N}-x_{D, s a t, M}, 0\right) N_{I I I}$ \\
\hline 17 & $x_{D, s a t, M}$ & $x_{D, s a t, M}=\frac{C_{D, s a t, M}}{\bar{\rho}_{n}}$ \\
\hline 21 & $\mathfrak{M}_{i}$ & $\mathfrak{M}_{i}=x_{\mathrm{H}_{2} \mathrm{O}, i} \mathfrak{M}_{S \operatorname{Sln} K O H}+x_{\mathrm{H}_{2}, i} \mathfrak{M}_{\mathrm{H}_{2}}+x_{\mathrm{O}_{2}, i} \mathfrak{M}_{\mathrm{O}_{2}}$ \\
\hline 25 & $\mathfrak{M}_{S \operatorname{Sln} K O H}$ & $\mathfrak{M}_{S \ln K O H}=\left(\frac{1-C}{\mathfrak{M}_{\mathrm{H} 2 \mathrm{O}}}+\frac{C}{\mathfrak{M}_{\mathrm{KOH}}}\right)^{-1}$ \\
\hline 26 & $\dot{V}_{m}$ & $\dot{V}_{m}=\dot{V}_{r}$ \\
\hline 28 & $\dot{V}_{D, r_{z}}$ & $\dot{V}_{D, r_{z}}=\dot{n}_{D, r_{z}} \frac{R T}{P_{N_{D}}}$ \\
\hline 30 & $\dot{n}_{F, r_{z}}$ & $\dot{n}_{F, r_{z}}=\sigma_{F, r_{z}} r$ \\
\hline 34 & $\dot{V}_{\mathrm{H}_{2} \mathrm{O}, r_{z}}$ & $\dot{V}_{\mathrm{H}_{2} \mathrm{O}, r_{z}}=\frac{\dot{n}_{\mathrm{H} 2 \mathrm{O}, r_{z}} \mathfrak{M}_{\mathrm{H} 2} \mathrm{O}}{\rho_{\mathrm{H} 2} \mathrm{O}}$ \\
\hline 36 & $\dot{V}_{o}$ & $\dot{V}_{o}=\dot{n}_{o} \frac{R T}{P_{N}}$ \\
\hline 38 & $K_{S}$ & Taken from $[27]$ \\
\hline 39 & $f_{D}$ & $f_{D}=\left\{-2 \log \left[\frac{\epsilon}{3.71 I D}-\frac{5.02}{R e} \log \left(\frac{\epsilon}{3.71 I D}+\frac{14.5}{R e}\right)\right]\right\}^{-2}$ (turbulent flow [28]) \\
\hline 40 & $R e$ & $R e=\frac{\rho_{\operatorname{Sln} K O H} v_{S} I D}{\mu_{\operatorname{Sln} K O H}}$ \\
\hline 41 & $v_{S}$ & $v_{S}=\frac{1}{A_{S}} \frac{\dot{m}_{S}}{\rho_{S \ln K O H}}$ \\
\hline
\end{tabular}

Indexes: $D$ and $E: \mathrm{H}_{2}$ or $\mathrm{O}_{2}, F: \mathrm{H}_{2}, \mathrm{O}_{2}$ or $\mathrm{H}_{2} \mathrm{O}, n$ : flows 3 or $4, o$ : flows 5 or $6, r$ : flows 11 or 12 , $t$ : flows 15 o $16, z$ : reactions 1 (Cathodic side) or 2 (Anodic side), $M$ : PSs I or II, $N$ : PSs III or IV, $Q$ : PSs IX or X.

whose variables already belong to the basic structure of the model.

\subsubsection{Molar flow of $\mathrm{H}_{2}$ gas inside $S C$}

The molar flow $\dot{n}_{\mathrm{H}_{2}, 9}$ is analyzed as the rise of the bubbles immersed in the solution until they separate on the free surface of the liquid. It will be modeled as the gradual separation of the bubbles present in the liquid with a time constant $\tau_{b}$ to be adjusted, i.e.,

$$
\dot{n}_{\mathrm{H} 2,9}=\frac{n_{b}}{\tau_{b}} .
$$

\subsubsection{Molar transfer flux in SP XIII}

The molar transfer flux $\Phi_{\mathrm{H}_{2}}$ is calculated by the following constitutive equation, deduced directly from Fick's law [32]

$$
\Phi_{\mathrm{H}_{2}}=k_{x, \mathrm{H}_{2}, 7}\left(C_{\mathrm{H}_{2}, S C H}-C_{\mathrm{H}_{2}, B T P}\right)-k_{x, \mathrm{H}_{2}, 8}\left(C_{\mathrm{H}_{2}, B T P}-C_{\mathrm{H}_{2}, S C O}\right) .
$$


Table 7: Values of fixed parameters and constants. Piping dimensions are presented separately in Table 1. The parameters taken from the literature are referenced along with their values.

\begin{tabular}{|c|c|c|c|}
\hline Symbol & Value & Symbol & Value \\
\hline \multicolumn{4}{|c|}{ Parameters } \\
\hline$V_{m i x, N}$ & $1.71 \times 10^{-3} \mathrm{~m}^{3 a}$ & $\sigma_{\mathrm{H}_{2} \mathrm{O}, 1}$ & -2 \\
\hline$\sigma_{\mathrm{e}^{-}, 1}$ & -2 & $\sigma_{\mathrm{H}_{2}, 1}$ & 1 \\
\hline$\sigma_{\mathrm{OH}^{-}, 1}$ & 2 & $\sigma_{\mathrm{OH}^{-}, 2}$ & -2 \\
\hline$\sigma_{\mathrm{O}_{2,2}}$ & 0.5 & $\sigma_{\mathrm{H}_{2} \mathrm{O}, 2}$ & 1 \\
\hline$\sigma_{\mathrm{e}^{-}, 2}$ & 2 & $\eta_{\text {pump }, i}$ & $10 \%^{a}$ \\
\hline$\dot{W}_{i}$ & $26.7 \mathrm{~W}^{a}$ & $T$ & $300 \mathrm{~K}$ \\
\hline$\eta_{F}$ & $90 \%^{a}$ & $C$ & $30 \% \mathrm{w} / \mathrm{w}^{a}$ \\
\hline$D_{\mathrm{H}_{2}}$ & $1.3236 \times 10^{-7} \mathrm{~m}^{2} \mathrm{~s}^{-1}[29]$ & $D_{\mathrm{O}_{2}}$ & $4.4120 \times 10^{-8} \mathrm{~m}^{2} \mathrm{~s}^{-1}[29]$ \\
\hline$K_{H e, \mathrm{H}_{2}}$ & $8.3355 \times 10^{-6} \mathrm{~mol} \mathrm{~m}^{-3} \mathrm{~Pa}^{-1}[29]$ & $K_{H e, \mathrm{O}_{2}}$ & $1.6816 \times 10^{-5} \mathrm{~mol} \mathrm{~m}^{-3} \mathrm{~Pa}^{-1}[29]$ \\
\hline$\epsilon_{\mathrm{H}_{2}}^{\text {Darcy }}$ & $\begin{array}{l}1.4 \times 10^{-16} \times P_{\mathrm{H}_{2}} \mathrm{~mol} \mathrm{~m}^{-1} \mathrm{~s}^{-1} \\
\mathrm{~Pa}^{-1}[30]\end{array}$ & $\epsilon_{\mathrm{O}_{2}}^{\operatorname{Darcy}}$ & $\begin{array}{l}0.7 \times 10^{-16} \times P_{\mathrm{O}_{2}} \mathrm{~mol} \mathrm{~m}^{-1} \mathrm{~s}^{-1} \\
\mathrm{~Pa}^{-1}[30]\end{array}$ \\
\hline$K_{\text {cell }}$ & $5^{a}$ & $\epsilon$ & $0.0024 \mathrm{~m}^{a}$ \\
\hline \multicolumn{4}{|c|}{ Constants } \\
\hline$R$ & $8.314 \mathrm{~kJ}(\mathrm{kmol} \mathrm{K})^{-1}$ & $\mathfrak{M}_{\mathrm{H}_{2}}$ & $2.016 \mathrm{~kg} \mathrm{kmol}^{-1}$ \\
\hline $\mathfrak{M}_{\mathrm{O}_{2}}$ & $31.998 \mathrm{~kg} \mathrm{kmol}^{-1}$ & $\rho_{S \ln K O H}$ & $1281.3 \mathrm{~kg} \mathrm{~m}^{3}$ \\
\hline$g$ & $9.81 \mathrm{~m} \mathrm{~s}^{-2}$ & & $96485.3365 \mathrm{C} \mathrm{mol}^{-1}$ \\
\hline $\mathfrak{M}_{\mathrm{H}_{2} \mathrm{O}}$ & $18.015 \mathrm{~kg} \mathrm{kmol}^{-1}$ & $\mathfrak{M}_{K O H}$ & $56.1056 \mathrm{~kg} \mathrm{kmol}^{-1}$ \\
\hline$\mu_{S \operatorname{SlnKOH}}$ & $0.0012 \mathrm{~kg}(\mathrm{~m} \mathrm{~s})^{-1}$ & & \\
\hline
\end{tabular}

${ }^{a}$ Measured and defined parameters of the prototype.

It should be recalled that the flux occurs between the midpoint (bulk) of the pressurization tank BTP and the midpoint (bulk) of each of the gas separation chambers. That point is indicated as $S C H$ and $S C O$ for the separation chambers of $\mathrm{H}_{2}$ and $\mathrm{O}_{2}$, respectively. The definition of the local molar transfer coefficient will be used

$$
k_{x, \mathrm{H}_{2}}=\frac{\mathfrak{D}_{\mathrm{H}_{2}, \mathrm{KOH}}}{z},
$$

being $z$ the distance that the solute must travel. Considering that the molarity $C$ can be expressed as the product of the molar concentration $x$ and the molar density $\bar{\rho}$, which are variables already analysed, 25 can be rewritten as

$$
\Phi_{\mathrm{H}_{2}}=\left[k_{x, \mathrm{H}_{2}, 7}\left(x_{\mathrm{H}_{2}, 7}-x_{\mathrm{H}_{2}, X I I I}\right)-k_{x, \mathrm{H} 2,8}\left(x_{\mathrm{H}_{2}, X I I I}-x_{\mathrm{H}_{2}, 8}\right)\right] \bar{\rho}_{\mathrm{SlnKOH}},
$$

which will be the constitutive equation to determine the material transfer by molecular diffusion of $\mathrm{H}_{2}$ throughout the equalization system. The molar transfer flux of the $\mathrm{O}_{2}$ will be similar taking into account that it diffuses from SCO to SCH:

$$
\Phi_{\mathrm{O}_{2}}=\left[k_{x, \mathrm{O} 2,7}\left(x_{\mathrm{O}_{2}, 7}-x_{\mathrm{O} 2, X I I I}\right)-k_{x, \mathrm{O} 2,8}\left(x_{\mathrm{O}_{2}, X I I I}-x_{\mathrm{O} 2,8}\right)\right] \bar{\rho}_{\mathrm{SlnKOH}} .
$$

\subsubsection{Molar injection flow}

At times when water is injected, $\dot{n}_{20}$ is non zero and therefore, $\dot{n}_{7}=\dot{n}_{8}$ is no longer valid. What needs to be defined is what proportion of the injection flow 
circulates through each SC. For simplicity, considering the place where the injection line is connected to the recirculation line, it is established that the entire injection flow goes to the SCO.

\subsection{Parameter identification}

With the proposed structure, the identification of the free parameters was carried out, whose values appear in Table 7 . These parameters combine values obtained from the literature with identification by using the well-known least-squares method. The output errors, which measure the difference between model and experiments, are minimized in order to compute such parameters.

\subsection{Degrees of freedom analysis}

A solvable model is obtained when its degrees of freedom (the difference between the number of unknown variables and parameters, and equations) is null. The model presents 42 variables, 50 structural parameters and 49 functional parameters. There are 141 equations in total that equal the number of unknown variables and parameters. Therefore, the model is solvable.

\section{Model solution and result analysis}

The model is solved using Matlab ${ }^{\circledR}$. Based on the formulation described previously, several conditions of the electrolyzer have been simulated. Moreover, tests were developed at ITBA lab with an own prototype. These experiments consist of different imposed operation conditions in temperature, pressure and electric current in a wide range $\left(40-60{ }^{\circ} \mathrm{C}, 10-60\right.$ bar and 10-50 A, respectively). The obtained results allow to compare the response of this PBSM with operation data collected experimentaly from the prototype. In the following subsections, two different simulations are presented. First, the bubbles behaviour is analysed when valves are opened and the current changes. Secondly, processes of pressurization and operation are compared between simulations and real data. Also, in a previous work [19], simulations with two step-perturbations can be seen. These simulations show the response in the cell providing qualitative information that can be compared with the actual evolution.

\subsection{Simulation of bubbles evolution}

The following simulation has been developed to analyse the bubbles behaviour in the separation chamber as was described in Subsection 2.4.2. Figure 3 illustrates the response of the model including the valve opening. No experimental measurement exist for theses variables. Left side shows the pressure and level in the separation chamber. In the right side the molar flows inside the separation chamber can be seen. The largest molar flows $\dot{n}_{\mathrm{H}_{2}, 3}$ and $\dot{n}_{\mathrm{H}_{2}, 11}$ can be read in the left axis while molar flow $\dot{n}_{\mathrm{H}_{2}, 9}$ and bubble molar flow $\dot{n}_{\mathrm{H}_{2}, b}$ are in the right axis. When the valve is opened, on the left of the figure it can be seen that the level rises due to the sudden change in pressure. Then, it quickly decreases due to the discharge of bubbles which is observed on the right. Moreover, in Figure 4 there is a change of the electric current. On the left, it can be seen that, due to the increase of the electric current 


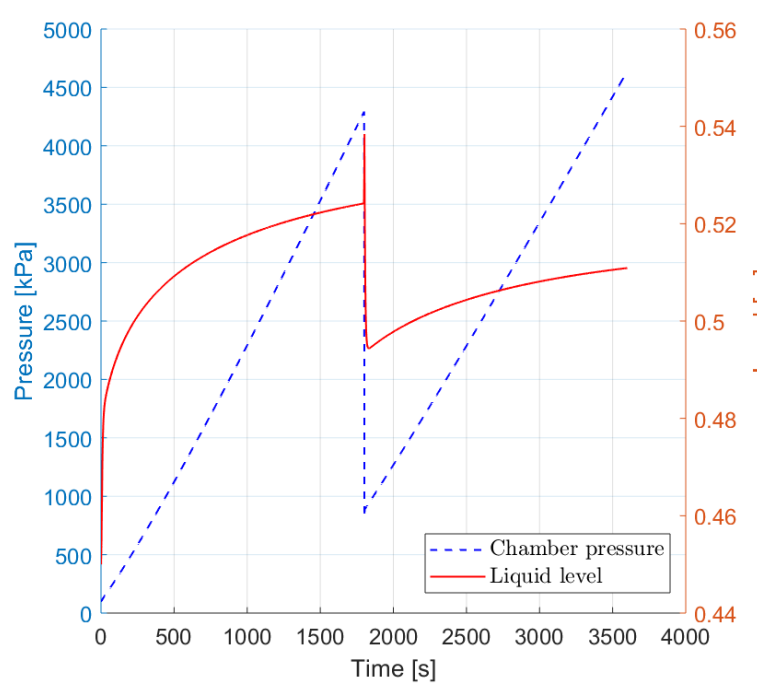

input, the slope of the saturation concentration rises due to the faster growth of the pressure. In turn, since there is more gas production, there are more bubbles in the system, which can be observed in the comparative zooms on the left and right between both lines. On the right, a peak in the bubbles molar flow can be seen due to the transient that is experienced until the flows in and out the separation chamber stabilize.

Figure 3: Model response in the $\mathrm{H}_{2}$ separation chamber to a valve opening.
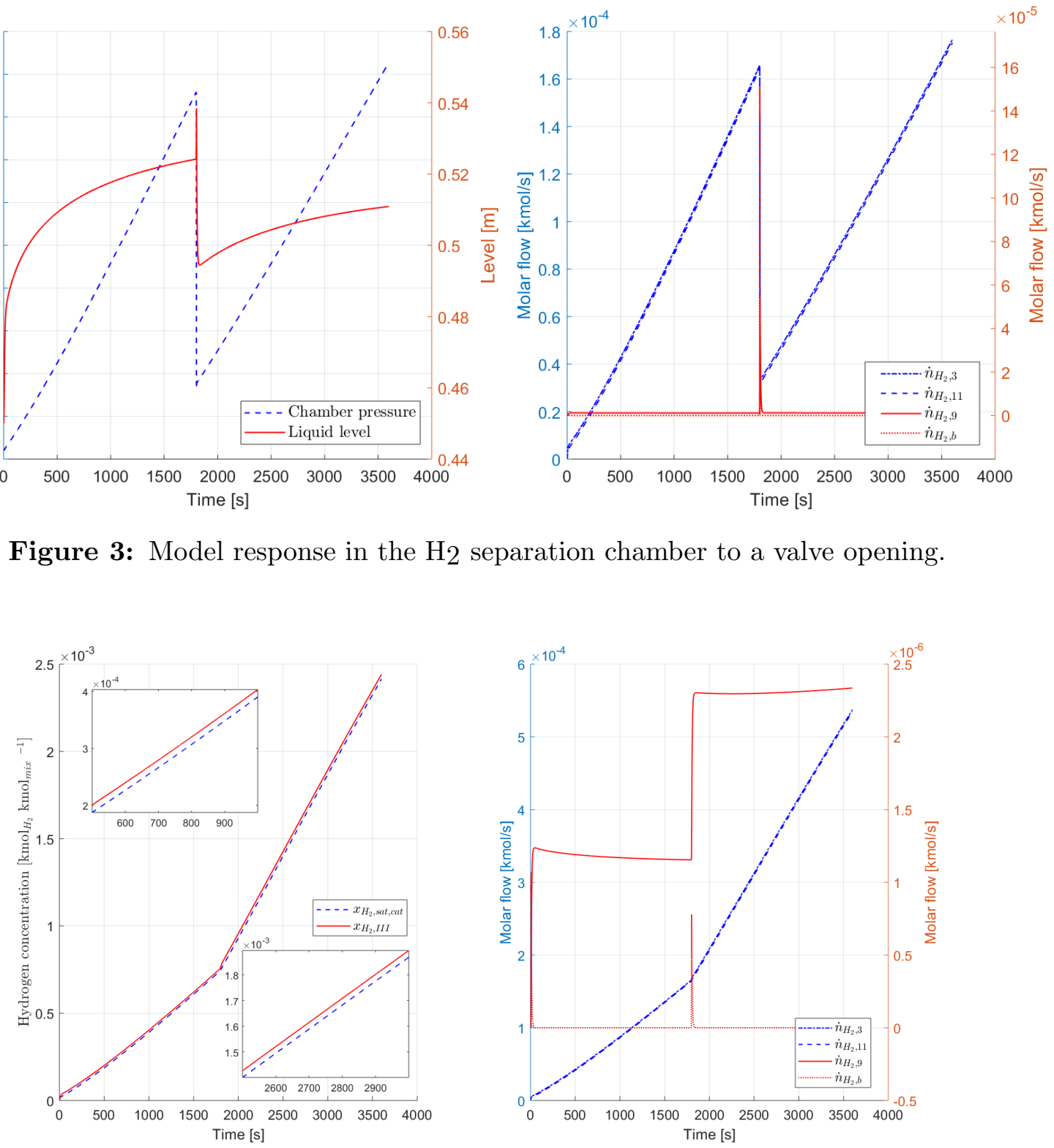

Figure 4: Model response in the $\mathrm{H}_{2}$ separation chamber to a electric current input change.

\subsection{Pressurization and operation tests}

Two typical tests of electrolyzer operation have been considered: i) pressurization from 1000 to $2000 \mathrm{kPa}$ and ii) normal operation at $1000 \mathrm{kPa}$. For both tests, 
experimental measurements are available. In the first case, represented in Figure 5 , the valves are closed while the approximately linear growth of the pressure is observed. Meanwhile, the hydrogen level decreases and the oxygen level increases as the equalization line compensates the higher production of $\mathrm{H}_{2}$ over $\mathrm{O}_{2}$. In this way it was possible to identify the curve of the level sensors and the Faraday efficiency. As it can be seen, the model response is quite close to the actual experimental points. This fact shows the model representation capabilities for this kind of test, similar to start-up or pressurization of the electrolyzer. The illustrated test was used for the model parameters identification. Afterwards, no more changes on parameter values were applied.

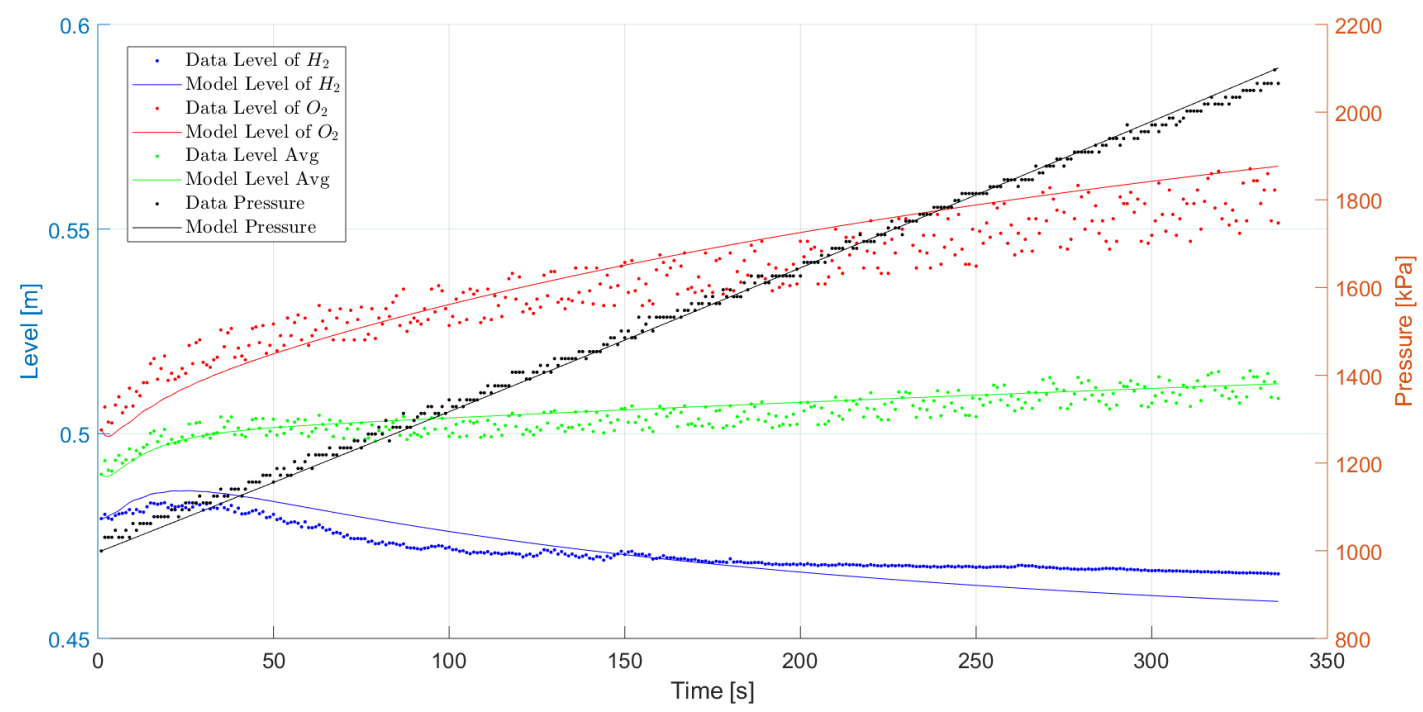

Figure 5: Comparison of pressurization between the real system (dotted line) and the model (solid line). In this case, the electrolyzer is operating with output valves closed.
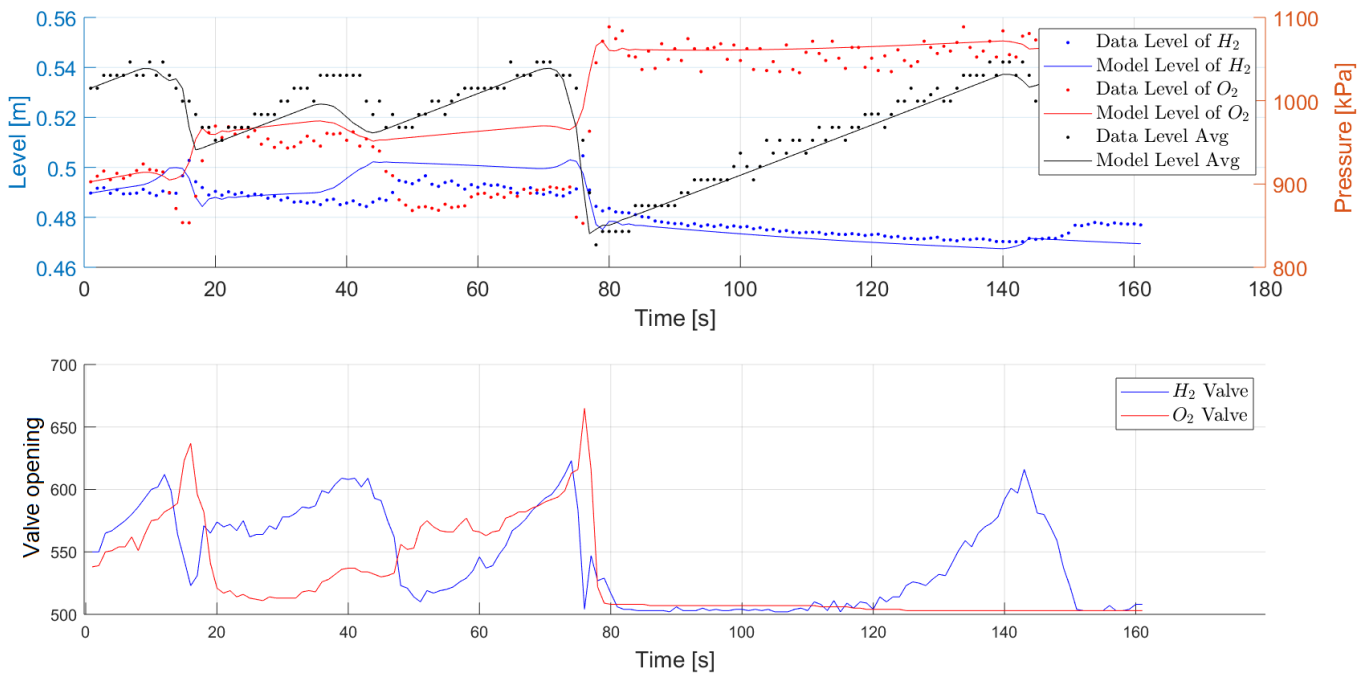

Figure 6: Upper figure: comparison of normal operation at $1000 \mathrm{kPa}$ between the real system (dotted line) and the model response (solid line). In the lower figure it can be seen the opening valves, above $u_{\min }=600$ the valve is open.

On the other hand, the period of operation shown in Figure 6 has been char- 
acterized by having openings and closures of the outlet valves that are controlled from the error in the desired working pressure and the level difference between both chambers. This original control has clear flaws as can be seen in the large depressurization that occurred starting from $t=75 \mathrm{~s}$. When opening a valve, the pressure of the assembly decreases while the level in the corresponding chamber increases due to the depressurization of that side and the compensation through the equalization line. In this case, the errors obtained are greater than the case of pressurization due to inaccuracies in the acquisition of valve positions and the lack of precision in level measurements, as observed from $t=40 \mathrm{~s}$ to $t=80 \mathrm{~s}$ in the modeled levels. These features show that there is more room to obtain a better fitting of the model when facing rapid changes in the operating conditions. However, the model has an adequate representation of the electrolyzer behavior under these operative conditions. This fact, in addition to the poor performance of the current controller indicates the necessity of a model-based controller for this complex process. Finally, designing a smoother control of the valves opening will assure smaller differences between pressures at both sides of the membrane and, consequently, less diffusion through it.

\section{Conclusions}

In this paper, an alkaline self-pressurized electrolyzer prototype is described in order to develop a phenomenological based semi-physical model. This modelling methodology presents additional information on the physical and chemical phenomena that occur in this system. This work allows us to better understand the design and operation of the electrolyzer. In addition, it provides tools to conduct a deeper analysis, e.g., controllability, observability and identifiability. The proposed model is capable of representing the dynamical evolution of the level, pressure and all the concentrations in the system, which additionally provides a proper simulation tool. Further work is focused on the design of a model-based controller synthesis for this equipment. The design of optimal control strategies based on this model could improve the gas quality by reducing gas cross-contamination. Moreover, the production of $\mathrm{H}_{2}$ and $\mathrm{O}_{2}$ at higher pressures will be possible if their purities are assured. To the best of the authors' knowledge, there has been no development yet of a complete phenomenological model as the one presented here.

\section{Declaration of competing interest}

The authors declare that they have no known competing financial interests or personal relationships that could have appeared to influence the work reported in this paper.

\section{Acknowledgement}

This work has been partially funded by the Cheerful CSIC project (MHE-200065). Furthermore, the authors appreciate the valuable conversations with Ricardo Laureta concerning the experimental work necessary to validate this model and the contribution of the Mechanical Eng. Dept. of ITBA. 


\section{References}

[1] United Nations Climate Change, The Paris agreement, https://unfccc. int/process-and-meetings/the-paris-agreement/the-paris-agreement (2016).

[2] J. Rogelj, M. den Elzen, N. Hhne, T. Fransen, H. Fekete, H. Winkler, R. Schaeffer, F. Sha, K. Riahi, M. Meinshausen, Paris Agreement climate proposals need a boost to keep warming well below $2^{\circ} \mathrm{C}$, Nature 534 (2016) 631-639.

[3] M. David, C. Ocampo-Martínez, R. Sánchez-Peña, Advances in alkaline water electrolyzers: A review, Journal of Energy Storage 23 (2019) 392-403.

[4] T. Mahlia, T. Saktisahdan, A. Jannifar, M. Hasan, H. Matseelar, A review of available methods and development on energy storage: technology update, Renewable and Sustainable Energy Reviews 33 (2014) 532-545.

[5] SBC Energy Institute, Electricity Storage FactBook, White paper, http://energystorage.org/resources/ sbc-energy-institute-electricity-storage-factbook (2013).

[6] R. Bhandari, C. Trundewind, P. Zapp, Life cycle assessment of hydrogen production via electrolysis - a review, Journal of Cleaner Production 85 (2014) $151-163$.

[7] T. Ogawa, M. Takeuchi, Y. Kajikawa, Analysis of trends and emerging technologies in water electrolysis research based on a computational method: A comparison with fuel cell research, Sustainability 10 (2018) 478-501.

[8] G. Yan, Y. Wang, Z. Zhang, Y. Dong, J. Wang, C. Carlos, P. Zhang, Z. Cao, Y. Mao, X. Wang, Nanoparticle-decorated ultrathin $\mathrm{La}_{2} \mathrm{O}_{3}$ nanosheets as an efficient electrocatalysis for oxygen evolution reactions, Nano-Micro Letters 12 (2020) 49.

[9] Y. Mao, W. Li, P. Liu, J. Chen, E. Liang, Topotactic transformation to mesoporous $\mathrm{Co}_{3} \mathrm{O}_{4}$ nanosheet photocathode for visible-light-driven direct photoelectrochemical hydrogen generation, Materials Letters 134 (2014) 276-280.

[10] O. Ulleberg, Modeling of advanced alkaline electrolyzers: a system simulation approach, International Journal of Hydrogen Energy 28 (2003) 21-33.

[11] E. Amores, J. Rodríguez, C. Carreras, Influence of operation parameters in the modeling of alkaline water electrolyzers for hydrogen production, International Journal of Hydrogen Energy 39 (2014) 13063-13078.

[12] A. Ursúa, P. Sanchis, Static-dynamic modelling of the electrical behaviour of a commercial advanced alkaline water electrolyser, International Journal of Hydrogen Energy 37 (2012) 18598-18614. 
[13] J. Milewski, G. Guandalini, S. Campanari, Modeling an alkaline electrolysis cell through reduced-order and loss-estimate approaches, Journal of Power Sources 269 (2014) 203-211.

[14] M. Hammoudi, C. Henao, K. Agbossou, Y. Dubé, M. Doumbia, New multiphysics approach for modelling and design of alkaline electrolyzers, International Journal of Hydrogen Energy 37 (2012) 13895-13913.

[15] P. Haug, B. Kreitz, M. Koj, T. Turek, Process modelling of an alkaline water electrolyzer, International Journal of Hydrogen Energy 42 (2017) 15689-15707.

[16] A. Roy, S. Watson, D. Infield, Comparison of electrical energy efficiency of atmospheric and high-pressure electrolysers, International Journal of Hydrogen Energy 31 (2006) 1964-1979.

[17] P. Olivier, C. Bourasseau, P. B. Bouamama, Low-temperature electrolysis system modelling: A review, Renewable and Sustainable Energy Reviews 78 (2017) 280-300.

[18] M. Sánchez, E. Amores, D. Abad, L. Rodríguez, C. Clemente-Jul, Aspen plus model of an alkaline electrolysis system for hydrogen production, International Journal of Hydrogen Energy 45 (2020) 3916-3929.

[19] M. David, H. Alvarez, C. Ocampo-Martínez, R. Sánchez-Peña, Phenomenological based model of hydrogen production using an alkaline self-pressurized electrolyzer, in: 2019 18th European Control Conference (ECC), IEEE, 2019, pp. 4344-4349.

[20] E. Hoyos, D. López, H. Alvarez, A phenomenologically based material flow model for friction stir welding, Materials \& Design 111 (2016) 321-330.

[21] C. Zuluaga-Bedoya, M. Ruiz-Botero, M. Ospina-Alarcón, J. García-Tirado, A dynamical model of an aeration plant for wastewater treatment using a phenomenological based semi-physical modeling methodology, Computers \& Chemical Engineering 117 (2018) 420-432.

[22] L. Lema-Pérez, J. García-Tirado, C. Builes-Montaño, H. Alvarez, Phenomenological based model of human stomach and its role in glucose metabolism, Journal of Theoretical Biology 460 (2019) 88-100.

[23] H. Alvarez, R. Lamanna, P. Vega, S. Revollar, Metodología para la obtención de modelos semifísicos de base fenomenológica aplicada a una sulfitadora de jugo de caña de azúcar, Revista Iberoamericana de Automática e Informática Industrial 6 (2009) 10-20.

[24] E. A. Lopez-Acosta, O. A. Perez-Sierra, F. A. Ortega-Quintana, E. J. MontesMontes, M. N. Martinez-Miranda, Phenomenological based semi-physical model for the milk evaporation process, Advance Journal of Food Science and Technology 16 (2018) 81-91. 
[25] M. M. Hossain, L. Atanda, S. Al-Khattaf, Phenomenological-based kinetics modelling of dehydrogenation of ethylbenzene to styrene over a mg3fe $0.25 \mathrm{mn} 0$. 25al0. 5 hydrotalcite catalyst, The Canadian Journal of Chemical Engineering 91 (2013) 924-935.

[26] J. M. Arandes, M. J. Azkoiti, J. Bilbao, H. I. de Lasa, Modelling fcc units under steady and unsteady state conditions, The Canadian Journal of Chemical Engineering 78 (2000) 111-123.

[27] W. B. Hooper, The 2-k method predicts head losses in pipe fittings, Chemical Engineering 88 (1981) 96-100.

[28] M. Shacham, An explicit equation for friction factor in pipe, Industrial \& Engineering Chemistry Fundamentals 19 (1980) 228-229.

[29] M. Schalenbach, W. Lueke, D. Stolten, Hydrogen diffusivity and electrolyte permeability of the zirfon perl separator for alkaline water electrolysis, Journal of the Electrochemical Society 14 (2016) 1480-1488.

[30] M. Schalenbach, G. Tjarks, M. Carmo, W. Lueke, M. Mueller, D. Stolten, Acidic or alkaline? towards a new perspective on the efficiency of water electrolysis, Journal of the Electrochemical Society 11 (2016) 3197-3208.

[31] E. J. Henley, J. D. Seader, D. Keith Roper, Separation process principles. Chemical and biochemical operations, 3rd Edition, John Wiley \& Sons, Inc., 2011.

[32] R. Bird, W. Stewart, E. Lightfoot, Transport phenomena, 2nd Edition, John Wiley \& Sons, Inc., New York, 2007. 